\title{
Relationship of Urine Dopamine with Phosphorus Homeostasis in Humans: The Heart and Soul Study
}

\author{
Nisha Bansal ${ }^{\mathrm{a}}$ Chi-yuan Hsu Mary Whooley $^{\mathrm{a}-\mathrm{c}}$ Anders H. Berg ${ }^{\mathrm{d}}$ \\ Joachim H. Ix ${ }^{\mathrm{e}-\mathrm{g}}$ \\ Departments of a Medicine and ${ }^{\mathrm{b}}$ Epidemiology and Biostatistics, University of California, San Francisco, and ${ }^{\mathrm{C} S a n}$ \\ Francisco Veterans Affairs Medical Center, San Francisco, Calif., dDepartment of Pathology, Beth Israel Deaconess \\ Medical Center, Boston, Mass., e Nephrology Section, Veterans Affairs San Diego Healthcare System, ${ }^{\mathrm{f}}$ Department \\ of Medicine, Division of Nephrology, and 9Department of Family and Preventative Medicine, Division of \\ Preventative Medicine, University of California, San Diego, San Diego, Calif., USA
}

\section{Key Words}

Urine dopamine $\cdot$ Phosphorus $\cdot$ Kidney $\cdot$ Proximal tubule

\begin{abstract}
Background: Urine dopamine (DA) is produced in the proximal tubule and has been found to increase in response to dietary phosphorus intake, and to contribute to greater urinary phosphorus excretion in animal models. Whether urine DA is associated with phosphorus homeostasis in humans is uncertain. Methods: This was a cross-sectional study of 884 outpatients. DA was measured from 24-hour urine collections. We examined cross-sectional associations between urine DA and serum phosphorus, 24-hour urine phosphorus (as an indicator of dietary phosphorus absorption), fractional excretion of phosphorus (FEphos), fibroblast growth factor (FGF)-23, and parathyroid hormone (PTH). Models were adjusted for age, sex, race, eGFR, albuminuria, hypertension, heart failure, tobacco use, body mass index, and diuretic use. Results: Mean age was $66.6 \pm 11$ years and mean eGFR was $71 \pm 21.3 \mathrm{ml} / \mathrm{min} / 1.73 \mathrm{~m}^{2}$. The mean urine DA was $193 \pm 86$ $\mu \mathrm{g} /$ day, mean serum phosphorus was $3.6 \pm 0.6 \mathrm{mg} / \mathrm{dl}$, mean daily urine phosphorus excretion was $671 \pm 312 \mathrm{mg} / \mathrm{day}$,
\end{abstract}

and mean FEphos was $17 \pm 9 \%$. In adjusted models, each standard deviation higher DA was associated with $78.4 \mathrm{mg} /$ day higher urine phosphorus and $0.9 \%$ lower FEphos $(\mathrm{p}<$ 0.05 for both). There was no statistically significant association between urine DA, serum phosphorus, FGF-23 or PTH in adjusted models. Conclusions: Higher dietary phosphorus absorption is associated with higher urine DA in humans, consistent with animal models. However, higher urine DA is not associated with FGF-23 or PTH, suggesting that known mechanisms of renal tubular handling of phosphorus may not be involved in the renal dopamine-phosphorus regulatory pathway in humans.

Copyright $\odot 2012$ S. Karger AG, Basel

\section{Introduction}

Higher serum phosphorus concentrations have been linked to arterial calcification in the general population and in patients with chronic kidney disease (CKD), even at phosphorus concentrations within the normal laboratory reference range [1-3]. In vitro studies have suggested that higher phosphorus can induce vascular smooth

\section{KARGER}

Fax +41613061234

E-Mail karger@karger.ch

www.karger.com (c) 2012 S. Karger AG, Basel

0250-8095/12/0356-0483\$38.00/0

Accessible online at:

www.karger.com/ajn
Nisha Bansal, MD

Division of Nephrology, University of California, San Francisco

521 Parnassus Ave, Box 0532

San Francisco, CA 94143 (USA)

Tel. +1 415514 1122, E-Mail nisha.bansal@ ucsf.edu 
muscle cells to transform into osteoblast-like cells and to deposit calcium and phosphorus in the extracellular matrix, leading to arterial calcification [4]. Collectively, these findings have suggested that higher phosphorus levels may represent a novel vascular toxin, and have led to new interest in factors that may influence serum phosphorus levels in the general population.

The kidney plays an important role in phosphorus regulation. In response to the ingestion of phosphorus, there is a rapid increase in the urinary excretion of phosphorus [5]. Yet, mechanisms through which the kidney senses and responds to higher phosphorus remain incompletely understood. Animal studies have suggested that renal proximal tubule cells can sense a change in phosphorus concentration and in response, there is endogenous production of dopamine in the proximal tubule [6-8]. In addition, increases in urine dopamine may contribute to urine phosphorus excretion. In a study in rats fed a highphosphorus diet, urine phosphorus and urine dopamine excretion were both increased, while plasma dopamine was unchanged [9]. Another study of rats fed a high-phosphorus diet found that key enzymes involved in the activation of renal dopamine receptors were activated, which inhibited renal reabsorption of phosphorus [10]. Others have demonstrated that in rats fed a low-phosphorus diet, the fractional excretion of phosphate was greater in rats infused with parathyroid hormone $(\mathrm{PTH})$ plus dopamine than in those infused with PTH alone [11].

To our knowledge, no previous study has examined the relationship of urine dopamine with phosphorus homeostasis in humans. In the present study, we test the hypothesis that urine dopamine excreted in $24 \mathrm{~h}$ is associated with phosphorus regulation, as measured by serum phosphorus, 24-hour urine phosphorus excretion (a marker of dietary phosphorus absorption), fractional excretion of phosphorus (FEphos; reflecting renal reabsorption of phosphorus), fibroblast growth factor (FGF)23, and PTH, in adults with stable coronary heart disease (CHD) and a spectrum of kidney function ranging from normal to moderate CKD.

\section{Subjects and Methods}

\section{Study Design and Participants}

The Heart and Soul Study is an observational study designed to investigate the influence of psychosocial factors on the progression of CHD. Methods have been described previously [12]. Briefly, participants were recruited from outpatient clinics in the San Francisco Bay area if they met one of the following inclusion criteria: history of myocardial infarction, angiographic evidence of
$>50 \%$ stenosis in $\geq 1$ coronary vessels, evidence of exercise-induced ischemia by treadmill or nuclear testing, history of coronary revascularization, or documented diagnosis of CHD by an internist or cardiologist. Participants were excluded if they were not able to walk one block, had experienced myocardial infarction within the past 6 months, or were likely to move out of the area within 3 years. The study protocol was approved by the Institutional Review Boards of participating institutions, and all participants provided written informed consent. Between September 2000 and December 2002, 1,024 participants enrolled and underwent a day-long baseline study appointment that included a medical history, physical examination, and comprehensive health status questionnaire. Outpatient 24-hour timed urine collections and fasting (12-hour) morning venous blood samples were obtained at baseline. We excluded 67 participants with missing timed urine collections and another 73 due to missing baseline covariate data, providing a final analytic sample of $884(86 \%)$ participants for this analysis.

\section{Measurements}

Urine Dopamine

Details of the protocol for 24-hour urine collections have been described previously [13]. Briefly, participants received detailed instructions on accurate urine collection and specimen refrigeration. Subjects were asked to void at the end of their study appointment and to begin the collection from that point forward. Research personnel arrived at the patients' home $24 \mathrm{~h}$ after the timed collection was initiated to avoid overcollection or undercollection. If participants reported missing any urine or if collections were $<1$ or $>3$ liter, collections were repeated. If the subjects were unable to collect all urine for any reason or had urinary incontinence, their samples were deemed inadequate, and no urinary dopamine data were recorded for these subjects.

Urinary dopamine levels were measured with gas chromatography-mass spectrometry at the Associated Regional and University Pathologists laboratories, with headquarters in Salt Lake City [14]. The normal reference range for the dopamine assays is $60-$ $440 \mu \mathrm{g} / \mathrm{day}$. Because the detection limit was $1.0 \mu \mathrm{g} / \mathrm{dl}$, catecholamine levels for the participants whose excretion level was below this detection limit were coded as $1.0 \mu \mathrm{g} / \mathrm{dl}$ [15]. To ensure adequate sampling, we measured urinary creatinine levels in parallel and included only the participants who had a urinary creatinine value within the normal range $(0.8-2.1 \mathrm{~g} /$ day) [15].

\section{Markers of Phosphorus Homeostasis}

We evaluated serum phosphorus concentrations, 24-hour urine phosphorus excretion, and the urinary FEphos as outcomes of interest in this study. Serum phosphorus was measured using fasting morning blood specimens collected at the study visit using a Vitros 950IRC (Ortho Clinical Diagnostics, www.orthoclinical. com) with a measurement range of $0.3-13 \mathrm{mg} / \mathrm{dl}$ and a coefficient of variation of $3.5 \%$, as previously described [16].

Urine phosphorus was measured from 24-hour timed urine collections [13]. Urine was mixed thoroughly and 5-ml aliquots were stored at $-80^{\circ} \mathrm{C}$. Specimens were thawed and treated with $1 \mathrm{~mol} / \mathrm{l}$ of hydrochloric acid, and urine phosphorus was measured using a Cobas 6000 analyzer (Roche Diagnostics, www. roche.com) [16]. The lower limit of detection was $3.4 \mathrm{mg} / \mathrm{dl}$, and the coefficient of variation was $1.4-1.7 \%$ [16]. To calculate urine phosphorus excretion in $24 \mathrm{~h}$, the urine phosphorus concentra- 
tion $(\mathrm{mg} / \mathrm{dl})$ was multiplied by total 24 -hour urine volume (dl/ day).

The FEphos was calculated by the following equation: (urine phosphorus $\times$ serum creatinine)/(serum phosphorus $\times$ urine creatinine) $\times 100 \%$. Serum and urine creatinine were measured by the rate Jaffe method.

Plasma FGF-23 concentrations were measured using a C-terminal human ELISA (Immunotopics, San Clemente, Calif., USA) [17]. Measurements were made in duplicate and averaged. The intra-assay $\mathrm{CV}$ was $<5.1 \%$; the inter-assay $\mathrm{CV}$ was $10.0 \%$ at a concentration of $36.4 \mathrm{RU} / \mathrm{ml}$ and $12.7 \%$ at a level of $379 \mathrm{RU} / \mathrm{ml}$.

Plasma PTH levels were measured using the Roche Parathyroid Hormone immunoassay on an Elecsys E170 automated analyzer. The lower limit of detection was $6 \mathrm{pg} / \mathrm{ml}$. The CV of the assay was $1.8 \%$ at a concentration of $167 \mathrm{pg} / \mathrm{ml}$, and $3.0 \%$ at 20 $\mathrm{pg} / \mathrm{ml}$.

\section{Other Measurements}

Patient demographics and comorbid diseases were determined by questionnaires. Systolic and diastolic blood pressures were measured after $5 \mathrm{~min}$ of rest in subjects in the supine position by trained research personnel. Participants brought their medications to the study appointment, and were recorded by trained research personnel. Weight and height were measured in participants wearing light clothing and no shoes. Body mass index (BMI) was calculated as weight in kilograms divided by height in meters squared.

Serum cystatin C concentrations were measured with a particle-enhanced immunonephelometric assay [18] (N Latex Cystatin-C, Dade Behring, Inc., Deerfield, Ill., USA) and used to calculate estimated glomerular filtration rate (eGFRcys) with the following formula: eGFR $=76.7 \times$ cystatin $\mathrm{C}^{-1.19}$. This formula, which has been validated with comparison with iothalamatemeasured GFR in a pooled cohort of kidney disease studies, showed little bias and provided a non-creatinine-based method to adjust for kidney function for this study [19]. The intra-assay coefficient of variation was $<2.9 \%$ and inter-assay coefficient of variation was $<3.2 \%$ [20]. Urine albumin was measured using nephelometry and urine albumin/creatinine was calculated (mg/g) [21]. High sensitivity C-reactive protein (CRP) was measured with the Roche (Indianapolis, Ind., USA) and the Beckman Extended Range (Galway, Ireland) assays [22].

\section{Statistical Methods}

We elected to categorize participants into quartiles based on the distribution of 24-hour urine dopamine in our study sample. We compared baseline characteristics of the study population across dopamine quartiles using ANOVA for continuous normally distributed variables, Kruskal-Wallis for continuous skewed variables, and $\chi^{2}$ for categorical variables. We tested the graphical distribution of our outcome variables to confirm normality. Next, we used linear regression to examine the association between urine dopamine and each measure of phosphorus homeostasis, using the lowest urine dopamine quartile as the referent category. When associations were fairly linear across urine dopamine quartiles, we also examined urine dopamine as a continuous predictor variable (per standard deviation increase) to maximize statistical power. We developed a sequence of models. An initial model was unadjusted. Model 1 adjusted for age, sex, and race (black, white, or other). Model 2 additionally adjusted for eGFRcys and urine albumin/creatinine ratio. In our final model 3, we also included covariates that varied significantly $(\mathrm{p}<0.05)$ across urine dopamine quartiles which included: history of heart failure, tobacco use, BMI, and use of medications such as diuretics, angiotensin converting enzyme (ACE) inhibitors, and angiotensin receptor blockers (ARBs). We also performed exploratory analysis testing for interactions between urine dopamine and age, sex, race, and CKD, defined as eGFR $<60 \mathrm{ml} / \mathrm{min} / 1.73 \mathrm{~m}^{2}$ versus higher.

All analyses were conducted using STATA (version 11, College Station, Tex., USA). p values $<0.05$ were considered statistically significant for all analyses including interaction terms.

\section{Results}

Among the 884 study participants, the mean age was $67 \pm 11$ years, $18 \%$ were women, and the mean eGFRcys was $71 \pm 21 \mathrm{ml} / \mathrm{min} / 1.73 \mathrm{~m}^{2}$. The mean urine dopamine was $193 \pm 86 \mu \mathrm{g} / \mathrm{day}$, serum phosphorus was $3.6 \pm 0.6$ $\mathrm{mg} / \mathrm{dl}$, daily urine phosphorus excretion was $671 \pm 312$ mg/day, FEphos was $17 \pm 9 \%$, median FGF-23 was 42.9 (IQR 28.1-70.8) RU/ml, and mean PTH was $60 \pm 34$ pg/ $\mathrm{ml}$. Baseline characteristics of the study population by urine dopamine quartiles are shown in table 1. Those with higher daily urine dopamine excretion were younger and less likely to be white, had higher eGFR, less albuminuria, and higher BMI. They were more likely to smoke and less likely to have heart failure or to use diuretics or ACE inhibitors. Plasma dopamine and serum phosphorus levels did not differ significantly across urine dopamine quartile. Participants with higher urine dopamine had lower serum creatinine, higher 24-hour urine creatinine and lower FEphos. Participants with higher urine dopamine also had higher 24-hour urine phosphorus excretions. FGF-23 was higher and PTH was lower among participants with higher urine dopamine.

Table 2 shows a correlation matrix of daily urine dopamine excretion, serum phosphorus, daily urine phosphorus excretion, FEphos, eGFRcys, FGF-23, and PTH. Direct correlations of moderate strength were observed between urine dopamine and eGFRcys, urine phosphorus and urine dopamine, and urine phosphorus and FEphos, whereas moderate inverse correlations were observed between eGFRcys and FEphos, eGFRcys and FGF23, and eGFRcys and PTH.

We did not observe a statistically significant association between 24-hour urine dopamine excretion with serum phosphorus concentrations; results were similar in both unadjusted and adjusted models (table 3). In contrast, we observed a statistically significant direct association of daily urine dopamine excretion with daily 
Table 1. Baseline characteristics of study population by urine dopamine quartiles $(n=884)$

\begin{tabular}{|c|c|c|c|c|c|}
\hline Characteristic & $\begin{array}{l}\text { I } \\
(<133 \mu \mathrm{g} / \text { day }) \\
(\mathrm{n}=223)\end{array}$ & $\begin{array}{l}\text { II } \\
(133-185 \mu \mathrm{g} / \text { day }) \\
(\mathrm{n}=219)\end{array}$ & $\begin{array}{l}\text { III } \\
(186-241 \mu \mathrm{g} / \text { day }) \\
(\mathrm{n}=221)\end{array}$ & $\begin{array}{l}\text { IV } \\
(\geq 242 \mu \mathrm{g} / \text { day }) \\
(\mathrm{n}=221)\end{array}$ & $\mathrm{p}$ value \\
\hline Female, \% & 18 & 27 & 14 & 14 & 0.001 \\
\hline Race, $\%$ & & & & & 0.002 \\
\hline White & 63 & 62 & 65 & 53 & \\
\hline Other & 26 & 27 & 20 & 23 & \\
\hline Diabetes, \% & 28 & 27 & 23 & 28 & 0.6 \\
\hline Hypertension, \% & 74 & 75 & 64 & 72 & 0.05 \\
\hline Prior myocardial infarction, $\%$ & 54 & 54 & 52 & 57 & 0.7 \\
\hline Prior congestive heart failure, $\%$ & 23 & 18 & 14 & 15 & 0.04 \\
\hline Current tobacco use, $\%$ & 14 & 20 & 16 & 29 & 0.001 \\
\hline Systolic blood pressure, $\mathrm{mm} \mathrm{Hg}$ & $135(120,148)$ & $130(120,144)$ & $130(120,144)$ & $130(120,140)$ & 0.2 \\
\hline Diastolic blood pressure, $\mathrm{mm} \mathrm{Hg}$ & $74 \pm 11$ & $74 \pm 12$ & $75 \pm 11$ & $75 \pm 11$ & 0.4 \\
\hline BMI & $26.2(23.9,28.9)$ & $27.6(24.7,30.5)$ & $28.3(25.5,30.9)$ & $29.6(26,33.9)$ & $<0.001$ \\
\hline CRP, mg/l & $2(1,5)$ & $2(1,5)$ & $3(1,5)$ & $2(1,5)$ & 0.6 \\
\hline $\mathrm{eGFR}, \mathrm{ml} / \mathrm{min} / 1.73 \mathrm{~m}^{2}$ & $56(44,70)$ & $68(55,82)$ & $74(62,87)$ & $83(72,96)$ & $<0.001$ \\
\hline Serum creatinine, $\mathrm{mg} / \mathrm{dl}$ & $1.3 \pm 0.6$ & $1.1 \pm 0.3$ & $1.0 \pm 0.4$ & $0.9 \pm 0.2$ & $<0.001$ \\
\hline 24-hour urine creatinine, $\mathrm{mg} /$ day & $937 \pm 313$ & $1,077 \pm 354$ & $1,305 \pm 330$ & $1,476 \pm 421$ & $<0.001$ \\
\hline Urine albumin/creatinine, $\mathrm{mg} / \mathrm{g}$ & $12.7(7.4,37.1)$ & $8.7(5.1,17.5)$ & $8.4(5.0,16.1)$ & $7.1(3.9,12)$ & $<0.001$ \\
\hline Plasma dopamine, $\mathrm{pg} / \mathrm{ml}$ & $15(15,20)$ & $15(15,18)$ & $15(15,18)$ & $15(15,20)$ & 0.7 \\
\hline Serum calcium, mg/dl & $9.5 \pm 0.5$ & $9.5 \pm 0.5$ & $9.6 \pm 0.5$ & $9.6 \pm 0.5$ & 0.1 \\
\hline Serum phosphorus, mg/dl & $3.7 \pm 0.6$ & $3.7 \pm 0.6$ & $3.6 \pm 0.5$ & $3.7 \pm 0.6$ & 0.2 \\
\hline 24-hour urine phosphorus, $\mathrm{mg} /$ day & $476(343,675)$ & $597(432,772)$ & $667(496,834)$ & $847(557,1,044)$ & $<0.001$ \\
\hline
\end{tabular}

Data are mean $\pm \mathrm{SD}$ or median (IQR), unless otherwise indicated.

Table 2. Correlation matrix between urine dopamine, measures of phosphorus homeostasis and eGFRcys*

\begin{tabular}{|c|c|c|c|c|c|c|c|}
\hline Variables & $\begin{array}{l}\text { Urine } \\
\text { dopamine }\end{array}$ & $\begin{array}{l}\text { Serum } \\
\text { phosphorus }\end{array}$ & $\begin{array}{l}\text { 24-hour urine } \\
\text { phosphorus }\end{array}$ & FEphos & eGFRcys & FGF-23 & PTH \\
\hline Urine dopamine & 1.0 & & & & & & \\
\hline 24-hour urine phosphorus & 0.4 & 0.04 & 1.0 & & & & \\
\hline FEphos & -0.3 & -0.2 & 0.4 & 1.0 & & & \\
\hline eGFRcys & 0.4 & -0.1 & 0.2 & -0.4 & 1.0 & & \\
\hline PTH & -0.2 & -0.1 & -0.1 & 0.3 & -0.4 & 0.2 & 1.0 \\
\hline
\end{tabular}

* All presented correlations are Pearson's correlation coefficients. 
Table 3. Association of urine dopamine with measures of phosphorus homeostasis $(\mathrm{n}=884)$

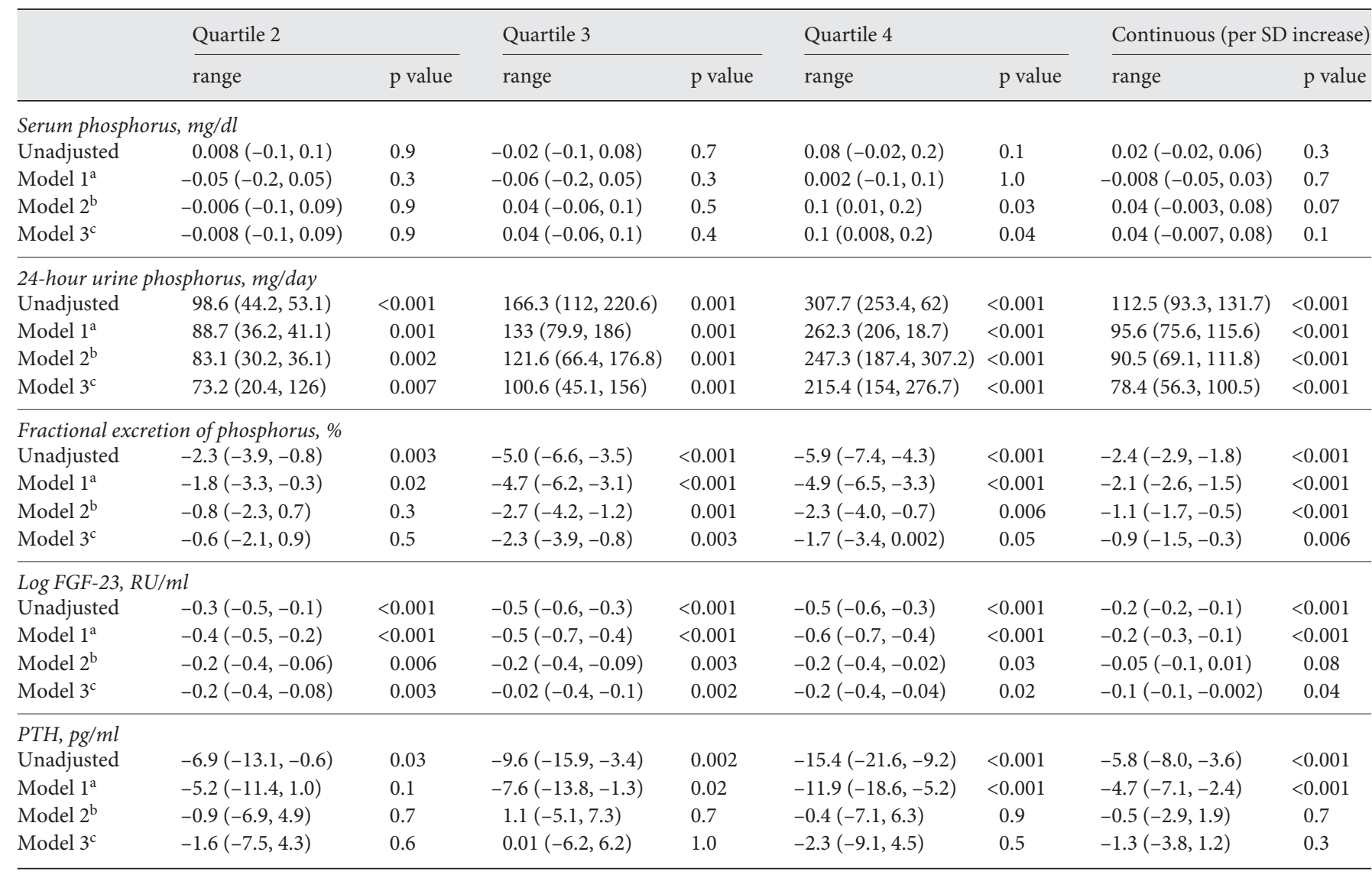

Quartile 1 was the referent category, with the lowest urine dopamine level. ${ }^{a}$ Adjusted for age, sex, and race (white, black, other). ${ }^{\mathrm{b}}$ Adjusted for age, sex, race (white, black, other), eGFRcys, and urine albumin/creatinine. ${ }^{c}$ Adjusted for age, sex, race, eGFRcys, urine albumin/creatinine, ACE/ARB use, heart failure, tobacco use, BMI, and diuretic use.

urine phosphorus excretion. In unadjusted models, each standard deviation higher urine dopamine excretion was associated with a 113 (95\% CI 93-132) mg/dl higher daily urine phosphorus excretion $(\mathrm{p}<0.001)$. This association remained similar throughout the sequence of adjusted models. We also observed a statistically significant association between higher daily urine dopamine excretion and lower FEphos. Each standard deviation higher daily urine dopamine excretion was associated with approximately $1 \%$ lower FEphos in fully adjusted models. We explored associations between urine dopamine and FGF23. In unadjusted models, higher urine dopamine was associated with lower FGF-23; however, this association was attenuated after adjustment for eGFRcys and urine albumin/creatinine. Similarly, the association between higher urine dopamine and lower PTH was statistically significant in unadjusted models and models adjusted for age, sex, and race; however, after adjustment for eGFRcys and urine albumin/creatinine, the association was rendered no longer statistically significant.

Given a direct association of urine dopamine with urine phosphorus excretion, but an inverse association with FEphos, we explored the association between urine dopamine and serum and urine creatinine. We found that each standard deviation higher urine dopamine was independently associated with $6.5 \mathrm{mg} / \mathrm{dl}$ higher urine creatinine (95\% CI 3.5-9.5, p <0.001) and $0.06 \mathrm{mg} / \mathrm{dl}$ lower serum creatinine $(95 \% \mathrm{CI}-0.06$ to $-0.04, \mathrm{p}<0.001$ ) in models adjusted for age, sex, race, eGFRcys, urine albu$\mathrm{min} /$ creatinine, ACE/ARB use, heart failure, tobacco use, $\mathrm{BMI}$, and diuretic use.

The relationships of daily urine dopamine excretion with serum phosphorus, 24-hour urine phosphorus excretion, FEphos, FGF-23, and PTH were all similar by 
age, sex, and race ethnicity ( $\mathrm{p}$ value for interactions all $>0.05$ ).

The associations of daily urine dopamine excretion with serum phosphorus, daily urine phosphorus excretion, and FGF-23 were also similar among persons with and without CKD ( $\mathrm{p}$ value for interactions all $>0.05$ ). However, we observed that the association of 24-hour urine dopamine excretion with FEphos was modified by CKD status. While higher urine dopamine was associated with lower FEphos in both those with and without $\mathrm{CKD}$, the association was stronger in those with eGFR $<60 \mathrm{ml} / \mathrm{min} / 1.73 \mathrm{~m}^{2}$ ( $\mathrm{p}$ value for interaction $=0.02$ ). In adjusted models, each standard deviation higher urine dopamine was associated with a 2.8\% lower FEphos ( $\mathrm{p}=$ 0.003 ) in persons with CKD and a $0.8 \%$ lower FEphos among persons without CKD $(\mathrm{p}=0.004)$. Additionally, we observed that the association of urine dopamine excretion with PTH was modified by CKD status ( $p$ value for interaction $<0.001$ ). In adjusted models, each standard deviation higher urine dopamine was associated with $13 \mathrm{pg} / \mathrm{ml}$ lower PTH in persons with CKD ( $\mathrm{p}=$ 0.002 ), whereas each standard deviation higher urine dopamine was not associated with PTH in persons without CKD $(\mathrm{p}=0.6)$.

\section{Discussion}

Several studies in rodents have suggested that urine dopamine may influence phosphorus homeostasis. However, to our knowledge, similar relationships have not previously been evaluated in humans. In a relatively large sample of community-living individuals with a spectrum of kidney function ranging from normal to moderate $\mathrm{CKD}$, we found that higher 24-hour urine dopamine excretion was associated with higher urine phosphorus excretion; a marker of dietary phosphorus absorption. Simultaneously, higher 24-hour urine dopamine was associated with lower FEphos. No association was observed between urine dopamine excretion and serum phosphorus concentrations, FGF-23, PTH levels, nor with serum dopamine concentrations. This suggests that greater dietary absorption of phosphorus is associated with renal generation of dopamine; however, greater dopamine is not associated with a higher FEphos. Urine dopamine does not appear to be associated with PTH or FGF-23, suggesting that other regulatory mechanisms may be driving the association between dietary phosphorus absorption and urine dopamine production.
The direct association of urine dopamine and phosphorus excretion most likely reflects greater generation of urine dopamine in response to greater dietary phosphorus consumption. Dopamine has been well documented to affect the activity of a number of transporters in the renal proximal tubule, including Npt2a, which is a major sodium-dependent phosphate transporter in the apical membrane of the proximal tubule cells [23]. Similar to our observations in humans, studies in rodent models have demonstrated that dietary phosphorus challenge leads to endogenous production of dopamine in the proximal tubule [6-9]. In one such study in rats, a change in dietary phosphorus intake from 0.7 to $1.8 \%$ increased urine dopamine excretion by $23 \%$; however, it did not change plasma dopamine levels [24]. Another study in mice found that the renal content of dopamine and the urinary excretion of dopamine was 2-3 times higher in animals on a high-phosphorus versus low-phosphorus diet [10]. Additionally, the investigators measured several enzymes involved in dopamine metabolism and found that the activity of three of the major dopamine-degrading enzymes - renalase, monoamine oxidase $\mathrm{A}$, and monoamine oxidase $\mathrm{B}$ - were decreased in response to a high-phosphate diet [10], suggesting that the increased urine dopamine levels may reflect decreased catabolism of urine dopamine.

Despite finding that greater urine dopamine excretion was associated with higher dietary phosphorus absorption, we found that greater 24-hour urine dopamine excretion was associated with a lower FEphos; an association that was stronger in subjects with CKD. There are several possible hypotheses to explain association of higher urine dopamine and lower FEphos. One is that urine dopamine is associated with higher dietary phosphorus and does not induce phosphaturia. Another hypothesis is that urine dopamine may affect tubular handling of creatinine, as suggested by the strong associations between urine dopamine and urine and serum creatinine, rendering the measure of FEphos unreliable. The negative association between urine dopamine and FEphos is in conflict with some studies in animal models [10]. In one study, rats fed a high-phosphorus diet for several days were infused with carbidopa (an inhibitor of an enzyme important for the biosynthesis of dopamine). FEphos decreased by $46 \%$ in the first $20 \mathrm{~min}$ [7]. These studies have suggested that dopamine inhibits a number of transporters in renal proximal tubule cells including Na-K-ATPase, Npt2a, and NHE3 [25, 26]. Other studies, however, are consistent with our results. One study found that inhibition of enzymes involved in urine dopamine 
availability did not alter urinary excretion of dopamine or phosphorus in either $3 / 4$ nephrectomized or sham rats, suggesting that urine dopamine does not play a significant role in the regulation of phosphorus handling by the kidney [27]. A study of rats which underwent bilateral renal denervation found that mean urinary phosphorus and urine dopamine excretion was similar compared to the rats who underwent sham surgery [9].

We did not observe an association between urine dopamine and FGF-23 or PTH. If confirmed, these findings may suggest that known mechanisms of renal tubular handling of phosphorus may not be involved in the renal dopamine-phosphorus regulatory pathway in humans. Similar findings have been suggested in animal models. For example, investigators infused inorganic phosphate into duodenal cells and found an increased urinary phosphorus excretion [28]. This phosphaturia was present even in rats who had parathyroidectomies, and measured levels of PTH and FGF-23 did not change in response to intestinal phosphate infusion [28], suggesting that additional unidentified phosphatonins or regulatory mechanisms linked to the gastro-intestinal tract may exist.

Our study had several strengths. We evaluated a large, well-characterized cohort of individuals with rigorously collected timed urine collections. Few cohort studies have collected data on urine dopamine and measures of phosphorus homeostasis. The study also has important limitations. All participants had CHD, were older, were mostly male, and few had advanced CKD. Results may differ in other populations. We did not have detailed dietary histories. This was a cross-sectional study, so causal inferences and directions of association cannot be determined.
In conclusion, greater urine dopamine excretion is associated with greater urinary phosphorus excretion in patients with stable CHD. This finding suggests that endogenous renal dopamine production may be increased in response to dietary phosphorus absorption. Urine dopamine was not associated with either FGF-23 or PTH, suggesting that known mechanisms of renal tubular handling of phosphorus may not be involved in the renal dopamine-phosphorus regulatory pathway in humans. Additional studies are needed to evaluate the mechanism for these associations and the significance of urine dopamine with CKD progression and vascular disease risk.

\section{Acknowledgements}

This study was supported by grants from the American Kidney Fund (N.B.), National Institute of Diabetes and Digestive and Kidney Diseases (K23 DK088865 to N.B. and K24 DK92291 to C.H.), National Heart Lung and Blood Institute (1R01HL096851) (J.H.I.), an American Heart Association Fellow-to-Faculty Transition Award (J.H.I.), and an award from the Sandra Daugherty Foundation (J.H.I.). The Heart and Soul Study was funded by the Department of Veterans Affairs, American Federation of Aging Research, Robert Wood Johnson Foundation, Nancy Kirwan Heart Research Fund, Ischemia Research and Education Foundation, and the NHLBI (R01 HL079235).

\section{Disclosure Statement}

None of the authors have any potential conflicts of interest. The results of this paper have not been published previously, in whole or in part, except in abstract form.

\section{References}

$>1$ Dhingra R, Sullivan LM, Fox CS, Wang TJ, D’Agostino RB Sr, Gaziano JM, Vasan RS: Relations of serum phosphorus and calcium levels to the incidence of cardiovascular disease in the community. Arch Intern Med 2007;167:879-885.

-2 Tonelli M, Sacks F, Pfeffer M, Gao Z, Curhan G: Relation between serum phosphate level and cardiovascular event rate in people with coronary disease. Circulation 2005;112: 2627-2633.

3 Palmer SC, Hayen A, Macaskill P, Pellegrini F, Craig JC, Elder GJ, Strippoli GF: Serum levels of phosphorus, parathyroid hor- mone, and calcium and risks of death and cardiovascular disease in individuals with chronic kidney disease: a systematic review and meta-analysis. JAMA 2011;305:11191127.

-4 Jono S, McKee MD, Murry CE, Shioi A, Nishizawa Y, Mori K, Morii H, Giachelli CM: Phosphate regulation of vascular smooth muscle cell calcification. Circ Res 2000; 87:E10-E17.

5 Marks J, Debnam ES, Unwin RJ: Phosphate homeostasis and the renal-gastrointestinal axis. Am J Physiol Renal Physiol 2010; 299:F285-F296.
6 Suzuki H, Nakane H, Kawamura M, Yoshizawa M, Takeshita E, Saruta T: Excretion and metabolism of dopa and dopamine by isolated perfused rat kidney. Am J Physiol 1984;247:E285-E290.

$\checkmark 7$ Debska-Slizien A, Ho P, Drangova R, Baines AD: Endogenous renal dopamine production regulates phosphate excretion. Am J Physiol 1994;266:F858-F867.

$>8$ Debska-Slizien A, Ho P, Drangova R, Baines AD: Endogenous dopamine regulates phosphate reabsorption but not NaK-ATPase in spontaneously hypertensive rat kidneys. J Am Soc Nephrol 1994;5:1125-1132. 
$>9$ Berndt TJ, Khraibi AA, Thothathri V, Dousa TP, Tyce GM, Knox FG: Effect of increased dietary phosphate intake on dopamine excretion in the presence and absence of the renal nerves. Miner Electrolyte Metab 1994;20: 158-162.

$>10$ Weinman EJ, Biswas R, Steplock D, Wang P, Lau YS, Desir GV, Shenolikar S: Increased renal dopamine and acute renal adaptation to a high-phosphate diet. Am J Physiol Renal Physiol 2011;300:F1123-F1129.

-11 Isaac J, Berndt TJ, Chinnow SL, Tyce GM, Dousa TP, Knox FG: Dopamine enhances the phosphaturic response to parathyroid hormone in phosphate-deprived rats. J Am Soc Nephrol 1992;2:1423-1429.

12 Whooley MA, de Jonge P, Vittinghoff E, Otte C, Moos R, Carney RM, Ali S, Dowray S, Na B, Feldman MD, Schiller NB, Browner WS: Depressive symptoms, health behaviors, and risk of cardiovascular events in patients with coronary heart disease. JAMA 2008;300: 2379-2388.

$\checkmark 13$ Ix JH, de Boer IH, Wassel CL, Criqui MH, Shlipak MG, Whooley MA: Urinary creatinine excretion rate and mortality in persons with coronary artery disease: the heart and soul study. Circulation 2010;121:1295-1303.

14 Arup laboratories: Catecholamines: Fractionated, plasma and urine free. www.aruplab.com/guides/clt/tests/clt_a 151. jsp\#1059229 (accessed January, 2012).

$\checkmark 15$ Otte C, Neylan TC, Pipkin SS, Browner WS, Whooley MA: Depressive symptoms and 24hour urinary norepinephrine excretion levels in patients with coronary disease: findings from the heart and soul study. Am J Psychiatry 2005;162:2139-2145.
16 Ix JH, Chonchol M, Laughlin GA, Shlipak MG, Whooley MA: Relation of sex and estrogen therapy to serum fibroblast growth factor 23, serum phosphorus, and urine phosphorus: the heart and soul study. Am J Kidney Dis 2011;58:737-745.

17 Jonsson KB, Zahradnik R, Larsson T, White KE, Sugimoto T, Imanishi Y, Yamamoto T, Hampson G, Koshiyama H, Ljunggren O, Oba K, Yang IM, Miyauchi A, Econs MJ, Lavigne J, Juppner H: Fibroblast growth factor 23 in oncogenic osteomalacia and $\mathrm{x}$ linked hypophosphatemia. N Engl J Med 2003;348:1656-1663.

18 Erlandsen EJ, Randers E, Kristensen JH: Evaluation of the Dade Behring N Latex Cys tatin $\mathrm{C}$ assay on the Dade Behring Nephelometer II System. Scand J Clin Lab Invest 1999;59:1-8.

19 Stevens LA, Coresh J, Schmid CH, Feldman HI, Froissart M, Kusek J, Rossert J, Van Lente F, Bruce RD 3rd, Zhang YL, Greene T, Levey AS: Estimating GFR using serum cystatin C alone and in combination with serum cre atinine: a pooled analysis of 3,418 individuals with CKD. Am J Kidney Dis 2008;51: 395-406.

20 Ix JH, Shlipak MG, Chertow GM, Whooley MA: Association of cystatin $\mathrm{C}$ with mortality, cardiovascular events, and incident heart failure among persons with coronary heart disease: data from the heart and soul study. Circulation 2007;115:173-179.

21 Ix JH, Chertow GM, Shlipak MG, Brandenburg VM, Ketteler M, Whooley MA: FetuinA and kidney function in persons with coronary artery disease - data from the heart and soul study. Nephrol Dial Transplant 2006;21: 2144-2151.
22 Whooley MA, Caska CM, Hendrickson BE, Rourke MA, Ho J, Ali S: Depression and inflammation in patients with coronary heart disease: findings from the heart and soul study. Biol Psychiatry 2007;62:314-320.

23 Cunningham R, Biswas R, Brazie M, Steplock D, Shenolikar S, Weinman EJ: Signaling pathways utilized by PTH and dopamine to inhibit phosphate transport in mouse renal proximal tubule cells. Am J Physiol Renal Physiol 2009;296:F355-F361.

24 Isaac J, Berndt TJ, Thothathri V, Tyce GM, Knox FG: Catecholamines and phosphate excretion by the remnant kidney. Kidney Int 1993;43:1021-1026.

25 Bacic D, Capuano P, Baum M, Zhang J, Stange G, Biber J, Kaissling B, Moe OW, Wagner CA, Murer H: Activation of dopamine D1-like receptors induces acute internalization of the renal $\mathrm{Na}+$ /phosphate cotransporter NaPi-IIa in mouse kidney and OK cells. Am J Physiol Renal Physiol 2005; 288:F740-F747.

26 Baines AD, Drangova R: Does dopamine use several signal pathways to inhibit $\mathrm{Na}-\mathrm{Pi}$ transport in OK cells? J Am Soc Nephrol 1998;9:1604-1612.

-27 Sampaio-Maia B, Moreira-Rodrigues M, Pestana M: Role of chronic inhibition of dopamine-metabolizing enzymes in the regulation of renal sodium and phosphate excretion in the rat remnant kidney. Nephron Physiol 2006;103:14-24.

28 Berndt T, Thomas LF, Craig TA, Sommer S, Li X, Bergstralh EJ, Kumar R: Evidence for a signaling axis by which intestinal phosphate rapidly modulates renal phosphate reabsorption. Proc Natl Acad Sci USA 2007;104: 11085-11090. 